\begin{tabular}{|cc|}
\hline WOOD & COMBUSTION \\
FLAMING & GLOWING \\
SMOKE & METHOXYPHENOLS \\
BENZENE & PHENOL \\
ANALYSIS & GC - MS \\
\hline
\end{tabular}

Open access revised manuscript version of Journal of analytical and applied pyrolysis 67 (2003) 135-141 Link to publisher: doi:10.1016/50165-2370(02)00058-X

\title{
Oxidative pyrolysis of integral softwood pellets
}

Maria Olsson, Jennica Kjällstrand and Göran Petersson

Continued applied studies were performed for chimney emissions from residential pellets burning 


\title{
Oxidative pyrolysis of integral softwood pellets
}

\author{
Maria Olsson, Jennica Kjällstrand, Göran Petersson* \\ Department of Chemical Environmental Science, Chalmers University of Technology, \\ SE-41296 Göteborg, Sweden
}

\begin{abstract}
Commercial wood pellets are increasingly used for residential heating. Characterisations were made of smoke components from oxidative pyrolysis of softwood pellets from compressed sawdust and wood shavings. Specific compounds released by flaming and glowing laboratory burning were sampled on Tenax cartridges and assessed by gas chromatography and mass spectrometry. Six lignin-related 2-methoxyphenols with antioxidant properties, together with 1,6-anhydroglucose from cellulose, were the major primary semi-volatile compounds released during flaming burning. Glowing combustion released benzene as the predominant aromatic compound.
\end{abstract}

Keywords: Wood pellets; Combustion; Tenax sampling; GC-MS; Methoxyphenols; Benzene 


\section{Introduction}

Wood pellets are made from compressed sawdust or wood shavings, originating mainly from sawmills and wood industry. The water content is typically only $8 \%$, which is less than half of that in traditional dry fuelwood. The uniform shape is cylindrical with a diameter of 6-8 $\mathrm{mm}$. In forested countries like Sweden, pellets are now rapidly replacing other fuels for residential stoves and boilers. Presently, about 100000 tonnes of softwood pellets are used yearly for small-scale heating in Sweden. This is remarkable in view of the only about ten years' short history of commercial wood pellets [1]. All these facts give reasons for studying identities and specific proportions of compounds formed by oxidative pyrolysis of wood pellets.

The lignin and polysaccharide components of wood give rise to very different compounds on thermal degradation [2]. Extensive research on controlled analytical pyrolysis of wood at low temperatures has identified a wide range of released compounds, structurally related to lignin [3] and polysaccharides [4]. The quantitative proportions of pyrolytic products have been used to characterise wood-related materials such as wood lignin [5], wood pulps [6] and forest biomass [7].

In the interval $400-1000^{\circ} \mathrm{C}$, the relative composition of compounds released from wood changes strongly and continuously [2], with decreasingly evident structural relationships between products and wood components. This parallels a maybe 100 -fold decrease of total emissions to air of organic compounds, including volatile hydrocarbons [8]. Residential burning of wood pellets includes mixed ignition, full flaming, and glowing phases within these ranges of temperatures and emissions. Flaming and glowing laboratory burning of a few pellets with air access was therefore thought to reflect both pyrolytic reactions and potential emissions to air.

Sampling on Tenax cartridges followed by thermal desorption onto the analytical column in a GC-MS system has recently been used successfully both for meat curing wood smoke [9] 
and for chimney smoke from wood burning [10]. An advantage compared to high-volume sampling methods for semi-volatile compounds in air [11] is that benzene can be determined simultaneously. This method could be favourably combined with the laboratory burning conditions wanted for pellets in this study.

\section{Experimental}

\subsection{Pellets and burning conditions}

The pellets studied by laboratory burning were obtained from $\mathrm{AB}$ Forssjö Bruk, Katrineholm, central Sweden (made mainly from dried sawdust), from Bioenergi i Luleå AB, northern Sweden (made from dried sawdust) and from Mellanskogs Bränsle AB, Söderhamn, central Sweden (made from wood shavings with $1 \%$ potato starch as binding additive). The raw materials were quantitatively unspecified mixtures of wood from Scots pine (Pinus sylvestris) and Norway spruce (Picea abies). All studied pellets had a water content of 8-10\% and were $8 \mathrm{~mm}$ in diameter, permitting uniform results to be obtained from a limited number of experiments (5-10 for each type of pellets).

For flame burning experiments, six pellets were placed on a steel net in a fume cupboard, and set aflame from below using a butane torch. Two additional pellets were added to the flaming fire, and the net with the burning pellets was placed in a 1.51 ceramic pot before sampling. Two pellets were then added during the first and one during the second half of the sampling period to simulate automatic feed in stove devices. Samples were taken $20-30 \mathrm{~cm}$ above the pellets and $10-20 \mathrm{~cm}$ above the fluctuating flames. For the experiments with glowing combustion, six pellets were burning freely on the net until flaming ceased. The net with the glowing pellets was then placed in the pot and samples were taken $10-15 \mathrm{~cm}$ above the pellets.

Temperatures were measured using a thermocouple instrument. They were variable up to $800^{\circ} \mathrm{C}$ in the pellets flames, and even below $400^{\circ} \mathrm{C}$ on the glowing pellets. 
Samples

Adsorbent cartridge

Gas chromatograph

Desorption

Column

Stationary phase

Oven temperature

Mass spectrometer

Mass spectra
: $20 \mathrm{ml}$ withdrawn during $4 \mathrm{~min}$ using an air pump

: Injector glass liner filled with $0.1 \mathrm{~g}$ of Tenax $\mathrm{TA}, 60-80$ mesh

: Varian 3800 with He as carrier gas, $1.1 \mathrm{ml} \mathrm{min}^{-1}, 10 \mathrm{psi}$

: Thermal, in the injector at $220^{\circ} \mathrm{C}$, with the carrier gas

: $30 \mathrm{~m} \times 0.25 \mathrm{~mm}$ i.d. FSOT (fused silica open tubular)

: Cyanopropylphenylsilicone, Rtx 1701, $0.25 \mu \mathrm{m}$ phase layer

: Increased $10^{\circ} \mathrm{C} \min ^{-1}$ from $-50^{\circ} \mathrm{C}$ to $50^{\circ} \mathrm{C}$ and $5^{\circ} \mathrm{C} \min ^{-1}$ from $50^{\circ} \mathrm{C}$ to $250^{\circ} \mathrm{C}$

: Varian Saturn 2000 , ion trap $\left(120^{\circ} \mathrm{C}\right)$, EI ionisation $(70 \mathrm{eV})$

: Mass range $m / z$ 50-300, one data-stored spectrum $\mathrm{s}^{-1}$

Quantitative proportions : Determined from integrated peak areas in the total ion current chromatograms

Absolute response $\quad$ : Estimated using methylbenzene from two different reference gases

Identifications

: By comparisons with previous studies $[7,10]$ and with NIST library support

\section{Results and discussion}

Flaming burning of wood pellets is followed by glowing combustion similarly as with traditional fuelwood. In modern residential stoves and burners with automatic continuous loading of wood pellets, these two burning modes occur simultaneously in fluctuating proportions. Their combustion characteristics are very different, however, and flaming and glowing burning were therefore studied separately. 


\subsection{Compounds released on flaming burning}

Relative proportions of prominent assessed compounds are reported in Table 1 for three different commercial brands of softwood pellets. The results refer to burning of a few pellets on the bottom of a ceramic pot with resulting limited air supply. The burning characteristics and the compound proportions were similar for the three types of pellets. The standard deviations for repeated experiments demonstrated good reproducibility.

The six reported 2-methoxyphenols, with the 4-hydroxy-3-methoxyphenyl (guaiacyl, Gu) structure were major primary thermal degradation products from the softwood lignin. Because of the uniform structure and analytical performance of the guaiacyl species, the assessed proportions of all compounds were related to the sum of these six compounds. Their total concentration was in the range $0.1-1 \mathrm{mg} \mathrm{m}^{-3}$. The major specific methoxyphenol was 4methyl-2-methoxyphenol $\left(\mathrm{GuCH}_{3}\right)$. Its concentration was typically twice as high as that of 2methoxyphenol (guaiacol, $\mathrm{GuH}$ ). The two most prominent alkenylphenols were $\mathrm{GuCH}=\mathrm{CH}_{2}$ and the trans isomer of $\mathrm{GuCH}=\mathrm{CHCH}_{3}$. Vanillin (GuCHO), as the major methoxyphenol with a carbonyl group, typically constituted $10 \%$ of the six methoxyphenols.

In Fig 1, the chromatographic separation of the six major and several additional minor methoxyphenols is illustrated. On choked burning of softwood at low temperature, the proportions of the late-eluting methoxyphenols are much higher [7]. In smoke from residential burning of softwood, $\mathrm{GuH}$ and $\mathrm{GuCH}_{3}$ are the predominant methoxyphenols [11]. Increasing combustion temperature evidently degrades reactive side-chains, leaving $\mathrm{GuH}$ and $\mathrm{GuCH}_{3}$ as the chemically most stable 2-methoxyphenols. Increasing combustion temperature in the range $600-800^{\circ} \mathrm{C}$ also decreases total methoxyphenol proportions of wood degradation products from predominant to almost negligible [2].

The interesting and often overlooked antioxidant properties of wood smoke methoxyphenols have recently been interpreted [12]. The four alkyl and alkenyl methoxyphenols have stronger antioxidant effects than GuH and GuCHO. Hardwood pellets 
Table 1

Average proportions of components in smoke from flaming burning of wood pellets (index 100 for the sum of the six prominent 4-hydroxy-3-methoxyphenyl or guaiacyl, $\mathrm{Gu}$, compounds).

\begin{tabular}{lccc}
\hline & $\begin{array}{c}\text { softwood sawdust } \\
\text { central Sweden } \\
6 \text { samples }\end{array}$ & $\begin{array}{c}\text { softwood sawdust } \\
\text { northern Sweden } \\
\text { 4 samples }\end{array}$ & $\begin{array}{c}\text { softwood shavings } \\
\text { 1\% starch } \\
\text { 3 samples }\end{array}$ \\
\hline Methoxyphenols & $16.5 \pm 2.3$ & 18.1 & 18.6 \\
GuH & $32.6 \pm 5.9$ & 38.3 & 39.6 \\
$\mathrm{GuCH}_{3}$ & $10.5 \pm 1.8$ & 10.6 & 12.1 \\
$\mathrm{GuCH}_{2} \mathrm{CH}_{3}$ & $13.7 \pm 1.7$ & 12.0 & 12.2 \\
$\mathrm{GuCHCH}_{2}$ & $16.6 \pm 5.2$ & 10.4 & 8.8 \\
$\mathrm{GuCHCHCH}_{3}(E)$ & $10.2 \pm 3.6$ & 10.5 & 8.7 \\
$\quad$ GuCHO, vanillin & $6.3 \pm 1.6$ & 5.3 & 7.2 \\
Carbohydrate-derived species & $20.3 \pm 3.2$ & 18.9 & 30.2 \\
2-Furaldehyde & & & \\
1,6-Anhydroglucose & $8.0 \pm 4.5$ & 8.0 & 7.4 \\
Volatile hydrocarbons & $5.9 \pm 1.8$ & 6.2 & 3.7 \\
Benzene & & & 3.6 \\
Methylbenzene & $3.4 \pm 1.1$ & 2.9 & 1.4 \\
Selected minor compounds & $2.1 \pm 1.3$ & 1.7 & \\
Phenol & & & \\
Naphthalene & & & \\
\hline
\end{tabular}




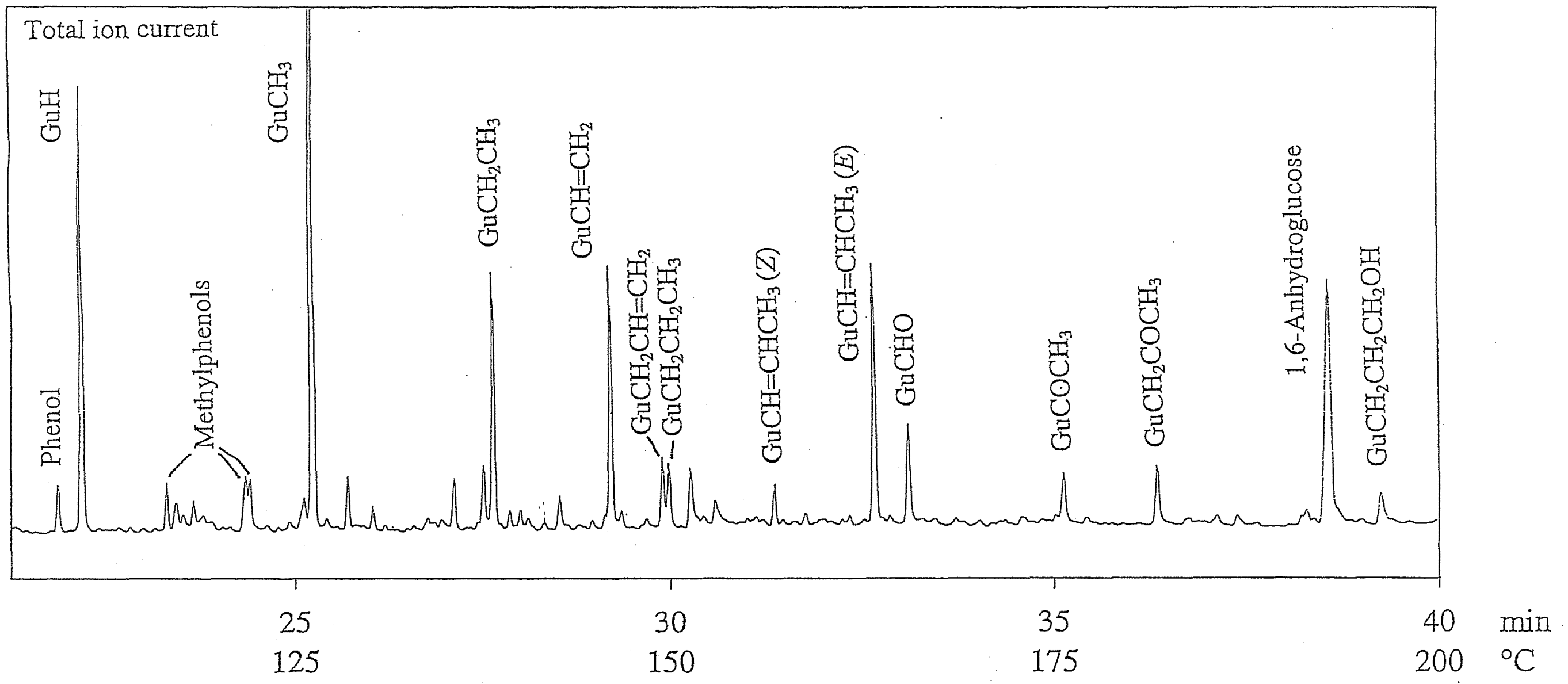

Fig. 1. Section of total ion current chromatogram illustrating the separation of 4-hydroxy-3-methoxyphenyl (guaiacyl, Gu) compounds from flaming burning of softwood pellets. 
were not studied but are expected to give rise to a set of 2,6-dimethoxyphenols from hardwood lignin in higher amounts than the corresponding 2-methoxyphenols $[6,7]$. The 2,6dimethoxyphenols have stronger antioxidant properties than their 2-methoxyphenol analogues [12]. The presence of antioxidants may render wood smoke from incomplete burning less hazardous than previously believed [12].

All smoke samples from flaming burning of wood pellets contained 1,6-anhydroglucose as a major semi-volatile component. This compound is predominant from thermal degradation of cellulose [6] and is present in smoke from a wide variety of biomass materials [13]. Its very polar nature makes quantitative determination by gas chromatography less reliable than for methoxyphenols. The high proportion from pellets with starch as adhesive may be due partly to formation from starch. Another characteristic polysaccharide degradation product was 2furaldehyde.

The two major aromatic hydrocarbons in smoke from flaming burning were benzene (0.01-0.1 $\mathrm{mg} \mathrm{m}^{-3}$ ) and methylbenzene (toluene). On the selected polar gas chromatographic column, they elute long before all phenols, as illustrated by chromatograms in recent studies $[9,10]$. Breakthrough of benzene was insignificant, as checked by low volume samples. Phenol as well as alkylphenols (Fig. 1), and naphthalene as well as more hazardous polycyclic aromatic hydrocarbons, were formed in comparatively low proportions. The relative proportions of all these compounds increase with increasing combustion temperature $[2,10,14]$. This is balanced by a rapid decrease of the primary degradation products from lignin and polysaccharides, as demonstrated both for controlled pyrolysis [2] and for chimney emissions [10].

\subsection{Compounds released on glowing burning}

After the flaming period, the pellets retained their shape with interior glowing combustion for at least as long time. The surface temperature was below $400^{\circ} \mathrm{C}$ as opposed to flame 
temperatures up to $800^{\circ} \mathrm{C}$ during flaming burning. No visible smoke was formed, and samples were taken inside the burning pot. Relative proportions are given in Table 2 for the most prominent assessed compounds.

The predominant component was the carcinogenic volatile hydrocarbon benzene. Benzene constitutes even more than $70 \%$ of the reported compounds, considering an observed lower GC-MS response for benzene relative to methylbenzene. The recorded concentrations indicated, however, that the benzene emissions were lower from glowing than from flaming burning. The ratio between benzene and methylbenzene was several times higher for glowing than for flaming burning, and also higher than for smoke from flaming stove burning of wood $[8,10]$. The proportions of naphthalene and phenanthrene as indicators of polycyclic aromatic hydrocarbons are much lower, as anticipated at the low combustion temperature $[2,10,14]$. Benzofuran and dibenzofuran were the most prominent oxygen-containing aromatic compounds, in remarkable contrast with flaming burning.

The predominance of benzene from glowing burning was unexpected, as was the almost complete absence of primary degradation products such as methoxyphenols and 1,6anhydroglucose. Evidently, the primary compounds are released completely during flaming burning of the compressed particles in the pellets. This contrasts with results for burning of solid wood [10]. The difference may be explained by a low thermal conductivity in solid wood during burning [15], whereas the space between the small wood particles in pellets may permit rapid heat and gas transfer. The proportion of oxygen and hydrogen relative to carbon is low for all the assessed compounds. This is compatible with strongly oxygen-deficient and hydrogen-deficient conditions in the glowing interior of the pellets.

The predominance of benzene necessitates consideration of emissions from glowing burning even if the total emissions from flaming burning are several times larger. For continuous pellets burning in residential appliances, the emissions are expected to reflect combined flaming and glowing combustion, at higher combustion temperatures than those 
Table 2

Average proportions (\%) of components in smoke from glowing remainders of wood pellets after flaming burning.

\begin{tabular}{lccc}
\hline & $\begin{array}{c}\text { softwood sawdust } \\
\text { central Sweden } \\
\text { 4 samples }\end{array}$ & $\begin{array}{c}\text { softwood sawdust } \\
\text { northern Sweden } \\
\text { 4 samples }\end{array}$ & $\begin{array}{c}\text { softwood shavings } \\
\text { 1\% starch } \\
\text { 2 samples }\end{array}$ \\
\hline Aromatic hydrocarbons & $69.6 \pm 1.7$ & 70.9 & 71.7 \\
$\quad$ Benzene & $11.2 \pm 3.3$ & 13.4 & 14.1 \\
Methylbenzene & $6.7 \pm 0.6$ & 5.5 & 4.6 \\
$\quad$ Naphthalene & $1.1 \pm 0.4$ & 1.3 & 1.1 \\
$\quad \begin{array}{l}\text { Phenanthrene } \\
\text { Benzofurans }\end{array}$ & $3.6 \pm 0.3$ & 3.8 & 3.8 \\
$\quad$ Benzofuran & $4.5 \pm 1.2$ & 2.6 & 1.7 \\
$\quad$ Dibenzofuran & $3.3 \pm 0.6$ & 2.6 & 3.0 \\
Nitriles & & & \\
Benzonitrile & & & \\
\hline
\end{tabular}


used for the pyrolytic experiments. The large difference in composition between emissions from flaming and glowing also emphasises the necessity of analytical data for emissions during different stages of combustion.

\section{Acknowledgement}

The financial support of the Swedish National Energy Administration is gratefully acknowledged.

\section{References}

[1] B. Hillring and J. Vinterbäck, For. Prod. J., 48 (1998) 67-72.

[2] R. Alén, E. Kuoppala and P. Oesch, J. Anal. Appl. Pyrolysis, 36 (1996) 137-148.

[3] O. Faix, D. Meier and I. Fortmann, Holz Roh-Werkstoff, 48 (1990) 281-285.

[4] O. Faix, I. Fortmann, J. Bremer and D. Meier, Holz Roh-Werkstoff, 49 (1991) 213-219.

[5] J. Rodrigues, D. Meier, O. Faix and H. Pereira, J. Anal. Appl. Pyrolysis, 48 (1999) 121-128.

[6] M. Kleen and G. Gellerstedt, J. Anal. Appl. Pyrolysis, 19 (1991) 139-152.

[7] J. Kjällstrand, O. Ramnäs and G. Petersson, Chemosphere, 41 (2000) 735-741.

[8] G. Barrefors and G. Petersson, Chemosphere, 30 (1995) 1551-1556.

[9] J. Kjällstrand and G. Petersson, Food. Chem., 74 (2001) 85-89.

[10] J. Kjällstrand and G. Petersson, Environ. Technol., 22 (2001) 391-395.

[11] S.B. Hawthorne, M.S. Krieger, D.J. Miller and M.B. Mathiason, Environ. Sci. Technol., 23 (1989) $470-475$.

[12] J. Kjällstrand and G. Petersson, Sci. Total Environ., 277(2001) 69-75.

[13] B.R.T. Simoneit, J.J. Schauer, C.G. Nolte, D.R. Oros, V.O. Elias, M.P. Fraser, W.F. Rogge and G.R. Cass, Atmos. Environ., 33 (1999) 173-182.

[14] A. Hauk, M. Sklorz, G. Bergmann and O. Hutzinger, J. Anal. Appl. Pyrolysis, 28 (1994) 1-12.

[15] J. Larfeldt, B. Leckner and M. C. Melaaen, Biomass Bioenergy, 18 (2000) 507-514. 